\title{
Pneumatic formwork used in strengthening of structural elements during reconstruction of buildings and structures
}

\author{
Susanna Abramyan ${ }^{1, *}$, Vladimir Polyakov ${ }^{1}$, and Oganes Oganesyan ${ }^{1}$ \\ ${ }^{1}$ Institute of Architecture and Civil Engineering of Volgograd State Technical University, 1 Akademicheskaya str., Volgograd, 400074, \\ Russia
}

\begin{abstract}
The paper discusses the importance of building reconstruction and the need for improving the available formwork systems used for strengthening of structural elements during reconstruction. Citing the results of the analysis of the Russian and foreign scientific publications, the authors emphasize the necessity of replacing costly wooden formworks with high-technology reusable all-purpose and mobile formwork systems. Considering that such requirements are met by rubber-fabric formworks, the authors have developed a pneumatic formwork and showed by way of experiment that the labor intensity of installation and dismantling of such formworks is much lower as compared with conventional wooden formworks, which makes this research original. The paper further describes the design of the suggested formwork and the installation and dismantling techniques. The versatility of the formwork is confirmed by its ability to easily adapt to any structural elements (pier foundations, columns, beams etc.) ensured by the flexibility of rubber-fabric materials. This system can be used for structural elements having various geometric shapes (round, rectangle, trapezoidal) and dimensions. Their transportability is warranted not only by the dimensions and flexibility, but also by a small weight. The use of pneumatic formworks contributes to resolving the problem of conservation such valuable natural material as wood.
\end{abstract}

\section{Introduction}

The increasing scopes of reconstruction of buildings and structures all around the world necessitate the invention of fundamentally new approaches to the performance of construction and installation works. This shift is facilitated not only by the use of new high-strength materials, such as composite reinforcement, fiber glass, microcement, composite concrete etc. [1-6], but also the availability of high-technology devices, appliances and fittings, which also defined the problematics considered in this paper. The analysis of the studies carried out by national and foreign scientists [7-11] shows that current reconstruction projects involve replacement of old wooden ceilings with reinforced concrete slabs and making superstructures after preliminarily enhancing the bearing capacity of underlying structural elements (foundations, columns, beams etc.). Thereby, the strengthening of columns alone avails of a plethora of conventional methods, such as: use of reinforced concrete or metallic collars; reinforced concrete collars with confinement reinforcement; vertical bracing; side relieving elements; reinforced concrete jacket; stressed clamps; welding steel angles on main reinforcement; removable relieving housing; reinforced concrete extensions etc. Some of the above methods are also used for strengthening of other structural elements. The choice of a particular method always depends on the condition of a respective structural element and the specifics of the technology used for the performance of the works.

However, with the advent of the recent innovations, the method of reinforced concrete extension has proved to be the most versatile as it may in fact be used for all of the above listed structures. This involves the use of a formwork system or extension of a structure by concrete spraying [12-14].

Whereas the construction using cast-in-situ structural elements relies on various formwork systems, reconstruction of buildings and structures uses mostly small-panel wooden forms, where labor inputs in installation and dismantling dramatically exceed the labor intensity of the main process: reinforcing and (where necessary) concreting. Also, as the experience shows, customized formworks are often have to be used, which is explained by non-identical damages of loadbearing structural elements.

The use of timber formwork is in itself associated with numerous inconveniences: low turnaround capacity, considerable consumption of timber, imperfect assembly and inferior quality of the surface of structures after concreting.

The analysis of certain works [15-19] shows that conventional wooden formworks are recently finding increasing competition on the part of permanent formwork systems made of corrugated sheets, polystyrene foam or chipboard, and large-scale reconstruction projects dealing with thin-wall shells of

\footnotetext{
* Corresponding author: susannagrant@mail.ru
} 
vault or dome structures opt for pneumatic formwork. These are pneumatic formworks that prove the most sophisticated and highly reusable.

Therefore, the relevance of this research is underlain by the need to introduce new formwork systems for reconstruction and overhaul of buildings and structures, because highly reusable formwork systems used for construction of new buildings are not always suitable for repair and refurbishment purposes.

\section{Main text}

\subsection{Goals and tasks}

Assuming that reconstruction is required to be based on a technology-savvy work process, which can be achieved through a reduction in its labor intensity, the goal of this research is to identify the methods for reducing labor inputs associated with the installation and dismantling of formworks during strengthening of certain structural elements using extension technologies, and for ensuring a high turnaround capacity of formwork systems.

The main tasks in the accomplishment of these goals were as follows: engineering of a pneumatic formwork for strengthening certain load-bearing structural elements (individual foundations, columns, beams, belts) of buildings and structures using extension technologies; evaluating the labor intensity of the installation and dismantling of such formworks using experimental methods.

\subsection{Pneumatic formwork for strengthening of structural elements during reconstruction of buildings and structures}

\subsubsection{Design of suggested pneumatic formwork}

A pneumatic formwork is a formwork consisting of a shape-forming air-supported flexible membrane.

Let us consider the design features of the suggested pneumatic formwork (fig. 1).

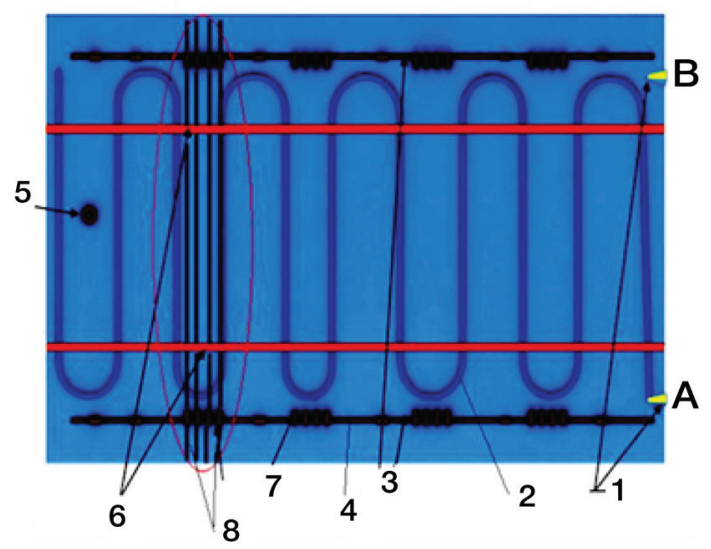

Fig. 1. Design of suggested formwork: 1- air supply valves; 2internal zigzag channel; 3- lashing straps with locks; 4- belt; 5injector; 6- additional lashing straps; 7- tubular holes in the belt; 8 - rigid bars
It consists of two layers of rubber-impregnated materials, which are normally used in the manufacturing of air bags, rigidly attached to each other along their edges (other special-purpose or reinforced vinyl textiles are also suitable for this purpose) [20, 21]. The formwork is provided with two valves (1) for air supply. Through the valve $A$, the air is supplied into the internal zigzag channel (2) of the formwork in to ensure it has the necessary rigidness before being finally installed in the design position.

The zigzag channel is formed by stitching two layers of a rubber-impregnated material, with a distance between the stitches of $10-15 \mathrm{~mm}$. In order to facilitate the preliminary fastening of the formwork in the design position, the formwork is tightened with a hook and loop fastener with a width of $100 \mathrm{~mm}$. The air is supplied through the valve $E$ only after the formwork is finally installed in the proper place and attached with lashing straps (3) having ratchet type locks. Lashing straps are fastened with the use of the belt (4). The concrete mixture is supplied through the injector (5).

To provide additional rigidness of the formwork (and consequently to appropriately shape the structure to be strengthened and achieving the necessary geometric dimensions), the formwork is provided with additional lashing straps (6) made of nylon. Before attaching the additional belts, rigid bars (8) are placed in the tubular holes (7) of the belt along the entire short side of the formwork.

If bare main reinforcement is found when strengthening structures, such reinforcement is provided with weld-on additional reinforcement using reinforcement stubs.

To preserve the protective layer and avoid damaging the formwork material, the additional reinforcement is fitted with plastic stops.

\subsubsection{Pneumatic formwork installation procedure by the example of strengthening a reinforced concrete column without additional reinforcement}

The scope of works associated with the operation of the suggested pneumatic formwork includes: ensuring the initial stability of the formwork before installation by supplying air through the valve $A$ (fig. 2); installation of the formwork, i.e. wrapping the column with the pneumatic formwork in such a way as to coordinate the injector with the damaged part of the column (fig. 3); preliminary fastening of the formwork with lashing straps (fig. 4), supplying air into the shell of the formwork through the valve 5 , final attachment (locking the lashing straps; making the formwork rigid with the use of the rigid bars, attaching the additional belts), supplying concrete through the injector and concreting the column. Before the installation, the surface of the pneumatic formwork which will contact the concrete is covered with emulsion grease. The formwork is dismantled after the concrete reaches at least $70 \%$ design strength. After that, the formwork is cleaned and assembled (fig. 5), i.e. wrapped in a roll for storage or transportation to another destination. 

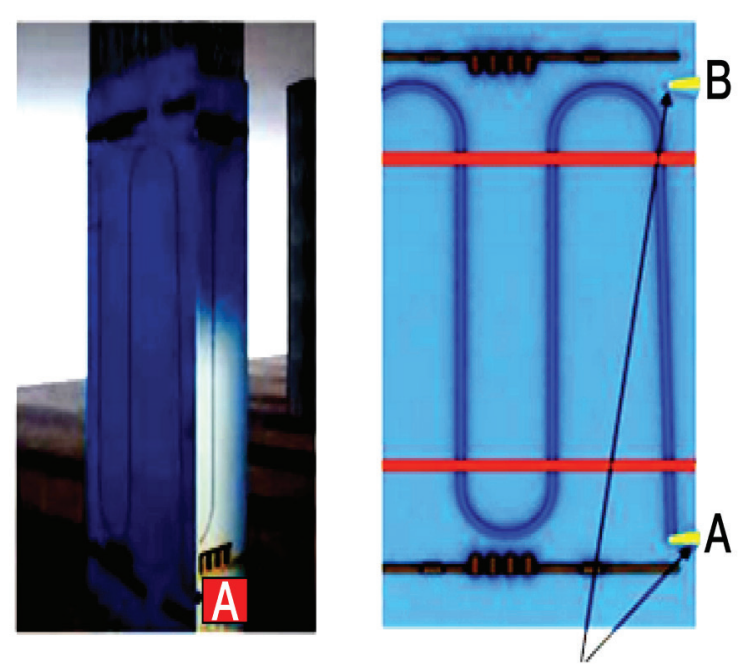

Fig. 2. Ensuring initial stability
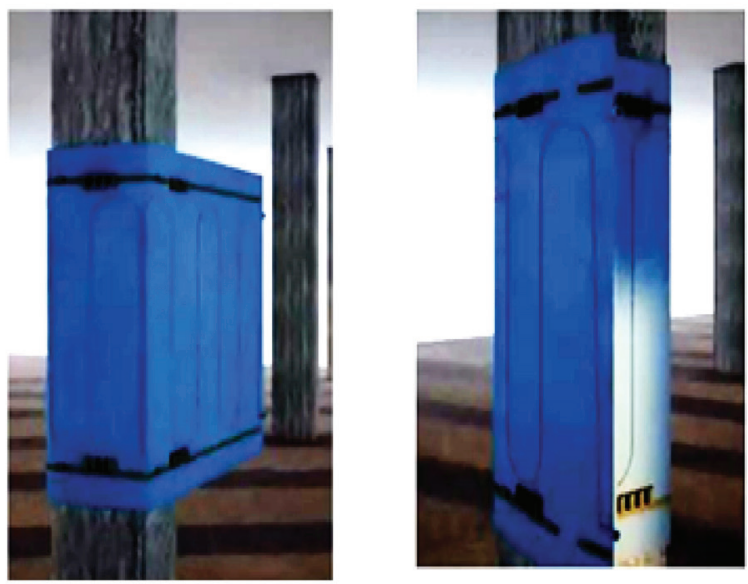

Fig. 3. Wrapping the column with the pneumatic formwork.
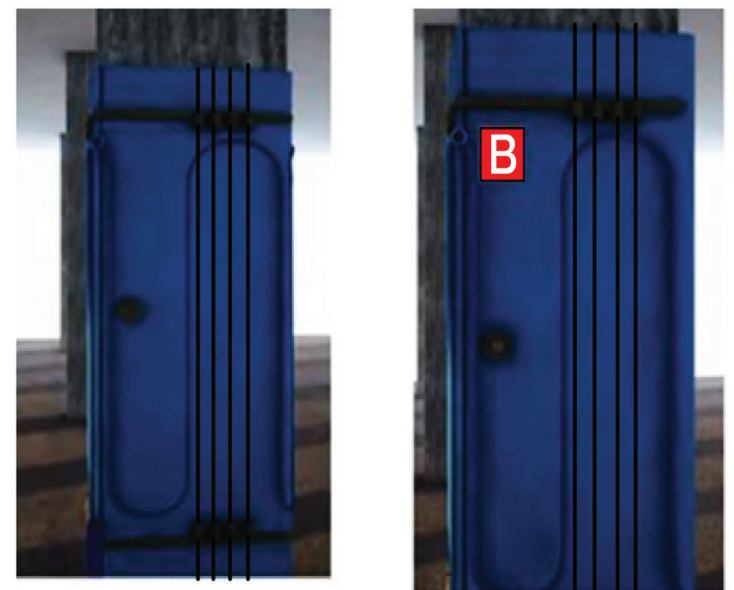

Fig. 4. Preliminary fastening of the formwork with lashing straps, supplying air info the shell of the formwork through the valve $\mathrm{B}$, final locking of the lashing straps.

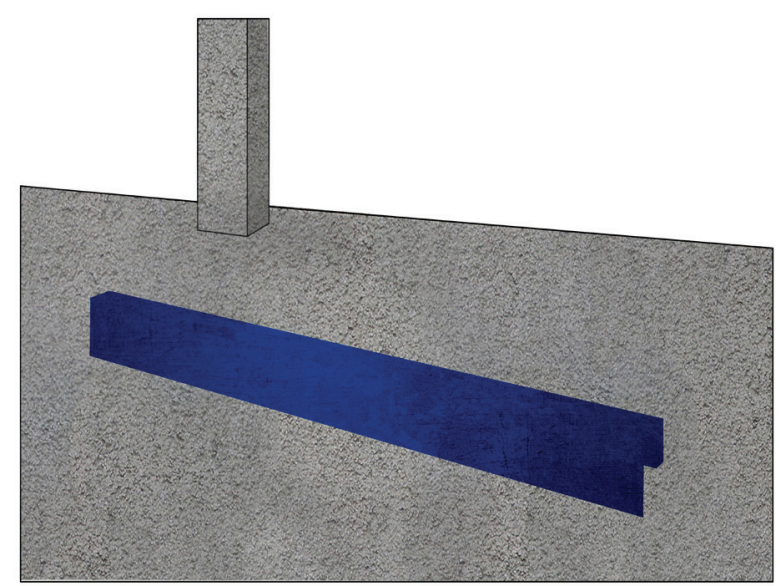

Fig. 5. The assembled pneumatic formwork

\section{Experimental part}

A model of the pneumatic formwork was built using the available materials (an inflated laminated vinyl mattress with dimensions $2 \times 1.5$ meters) in order to determine the labor intensity of its installation and dismantling. The only difference of the suggested structure consisted in that the internal zigzag channels in the formwork were replaced with reinforced $9 \mathrm{~mm}$ silicon tubes (fig. 6).

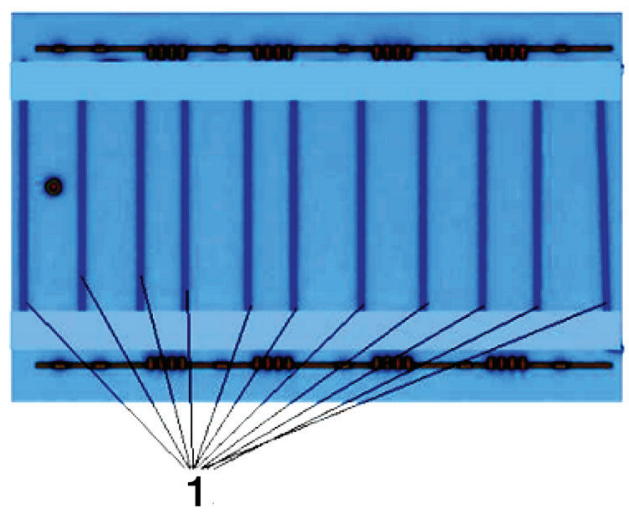

Fig. 6. Internal strengthening of experimental pneumatic formwork with silicon tubes (1).

Such tubes are used in medicine and food industry. The work was performed as follows: marking the place for installation of the formwork; placing the formwork preliminarily fixed with a hook and loop fastener, supplying the air by electric pump; fastening with lashing straps; placing rigid bars in the tubular holes of the belt, fastening with additional lashing straps.

The pneumatic formwork was installed on a column with a cross section $400 \times 400 \mathrm{~mm}$ by two workers. The thickness of the formwork after air inflation was $3 \mathrm{~cm}$. According to the time study, the labor intensity during the formwork installation was 0.28 man-hours, and the labor intensity during the dismantling was 0.19 manhours. The comparison of the labor intensity of installation and dismantling with regard to pneumatic and wooden formworks is visualized in fig. 7 . 


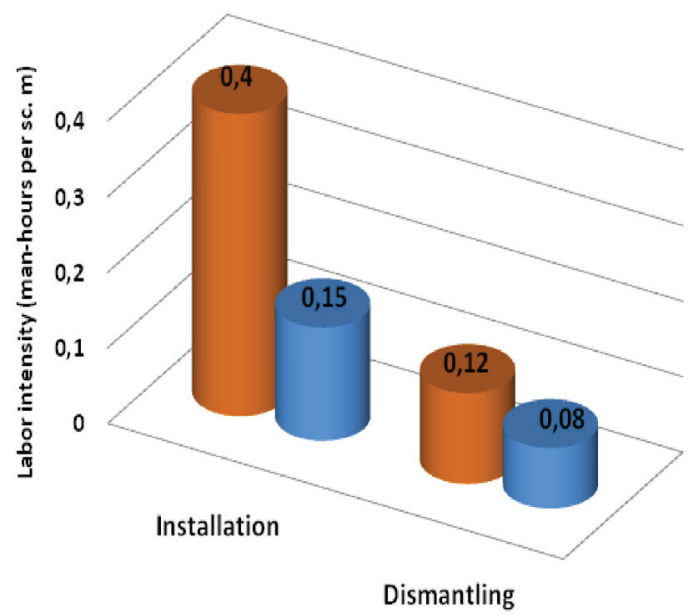

Wooden formwork Pneumatic formwork

Fig. 7. Labor intensity of installation and dismantling of pneumatic and wooden formworks, man-hours $/ \mathrm{m}^{2}$

The labor intensity of the installation and dismantling of wooden formwork was determined according to the effective regulatory documents.

The experimental studies have shown that the formwork is required to have air supply restrictors. They will allow unifying the use of formworks for structures (such as column, piers etc.) varying in the perimeter shape and configuration.

\section{Summary}

The research has shown that the use of innovations for improving labor productivity and saving materials and natural resources is one of the key focuses of repair and construction works during reconstruction of buildings and structures.

The theoretical and experimental studies conducted by the authors in writing this paper enabled them to make the following conclusion: the use of pneumatic formworks is namely one of the areas offering potential for reduction of costs while ensuring the appropriate quality of works.

This paper is original in that it suggests, for the first time, to use pneumatic formworks for strengthening of pier foundations, columns and beams as part of reconstruction of buildings and structures.

The research is practically relevant in that it has identified the key advantages of pneumatic formworks for strengthening structural elements, as it is installed and dismantled with lesser labor inputs as compared with wooden formworks, since wooden formworks often lose their stability during dismantling, with prevents their further use. Pneumatic formwork is easy to dismantle and can be fast cleaned of concrete sags. It fits all purposes and can be used for columns of any cross sections varying in the configuration and dimensions. It is transportable because it can be rolled and moved to another place with the least effort. And, what is no less important from the environmental point of view, the use of pneumatic formworks allows saving such valuable natural material as wood.

\section{References}

1. D. Lau, QW. Qiu, A. Zhou, CL Chow, Construction and Building Materials, 126, 573 (2016)

2. HY Shi, WQ Liu, H. Fang, Y. Bai, D. Hui, Composites Part B-Engineering, 108, 364 (2017)

3. WT Gan, LK GAO, SL Xiao, WB Zhang, XX Zhan, J. Li, Journal of Materials Science, 52, 3321 (2017)

4. S.G. Abramyan, R.Kh. Ishmametov, Procedia Engineering, 150, 2133 (2016)

5. M.N.Ibragimov, V.V.Sjomkin, A.V.Shaposhnikov, Academia. Architecture and construction, 4, 114 (2016) (In Russian)

6. A. A. Shilin, V. A. Pshenichnyj, D. V. Kartuzov, Prospects for Use of Composite Reinforcements, 181 (2007) (In Russian)

7. V. Pukhkal, V. Murgul, M. Garifullin, Procedia Engineering, 117, 624 (2015)

8. T. Wang, X. Zhong, XF Xu, Fundamental Research in Structural Engineering: Retrospective and Prospective, 1, 607 (2016)

9. P. Podnebesov, V Teryanik, Procedia Engineering, 150, 1733 (2016)

10. ZH Bian, SJ Fu, J. Li, Modeling and Computation in Engineering II, 197 (2013)

11. GQ Bi, Applied Mechanics and Materials, 438439, 711 (2013)

12. V. E. Rusanov, Bulletine of SibADI, 5 (27), 65 (2012) (In Russian)

13. V. Babichenko, V. Daneliuk, S. Kiriliuk, O. Poddubnyi, Modern Industrial and Civil Construction, 9 (no 3), 131 (2013)

14. I. Emelyanova, Bulletine of HNADU, 72, 107 (2016) (In Russian)

15. R. S. Fedjuk, Bulletine of RUDN, Series: Enig Surveys, 4, 105 (2013) (In Russian)

16. I. A. Rumyantseva, Bulletine of АГТУ, Series: Maritime Equipment and Technologies, 3, 112 (2015) (In Russian)

17. E.L. Ayrumyan, I.A. Rumyantseva, PGS 4, 25 (2007) (In Russian)

18. A.N., Malakhova, A.S. Balakshin, Bulletine of MGSU, 3, 81 (2013) (In Russian)

19. G.M. Bad'in, S.A. Sychev, Modern Building Construction and Reconstruction Technologies, 288 (2013) (In Russian)

20. D. Veenendaal, M. West, P. Block, Structural Concrete, 12 (3), 164 (2011)

21. V.N. Mel'kumov, A.N. Tkachenko, D.A. Kazakov, Scientific Herald of the VGASU, 3, 7 (2015) 